
\title{
$\checkmark$ Research Square \\ The Role of Spirituality in Symptom Experiences among Adults with Cancer
}

\author{
Megan Miller ( $\nabla$ Miller89@wisc.edu ) \\ University of Wisconsin-Madison https://orcid.org/0000-0001-7345-1687 \\ Kristine Kwekkeboom \\ University of Wisconsin-Madison \\ Catherine Cherwin \\ UI College of Nursing: The University of lowa College of Nursing
}

\section{Research Article}

Keywords: Symptoms, Spirituality, Oncology, Spiritual Well-Being

Posted Date: May 14th, 2021

DOl: https://doi.org/10.21203/rs.3.rs-427351/v1

License: (1) This work is licensed under a Creative Commons Attribution 4.0 International License. Read Full License

Version of Record: A version of this preprint was published at Supportive Care in Cancer on July 6th, 2021. See the published version at https://doi.org/10.1007/s00520-021-06399-z. 


\section{Abstract}

\section{Purpose}

Adults with cancer experience symptoms such as pain, fatigue, depression and sleep disturbance, which can impede quality of life. Research suggests that addressing spirituality may be one route to support holistic symptom management. The purpose of this study is to explore how spirituality relates to common cancer-related symptoms (including severity, distress, and interference) among a sample of adults with cancer.

Methods

This is a secondary analysis of data from $\mathrm{N}=200$ solid tumor cancer patients undergoing chemotherapy. Symptom experiences were assessed with a modified version of the Memorial Symptom Assessment Scale and the M. D. Anderson Symptom Inventory-Interference Subscale. Spirituality was assessed using a subset of items from the Fox Simple Quality of Life Scale. A series of ordinal and linear regressions were used to examine the relationship between spirituality and symptom severity, symptom-related distress and symptom interference across four cancer-related symptoms (pain, fatigue, depression and sleep disturbance).

Results

Higher spirituality trended toward an association with lower pain severity, although results were not significant $(p<.058)$. Higher spirituality was significantly associated with lower severity of fatigue ( $p$ $<.003)$, depression $(p<.006)$ and sleep disturbance $(p<.004)$. Spirituality was not significantly associated with any of the four symptom-related distress outcomes. Higher spirituality was significantly associated with lower overall symptom interference $(p<.004)$.

Discussion

This study highlights the role of spirituality in the experience of cancer-related symptoms. Additional research is needed among more diverse samples of people with cancer. This foundational work could lead to the development of symptom management interventions that incorporate aspects of spirituality.

\section{Introduction}

Despite innovations in supportive care, people with cancer experience significant symptoms such as pain, fatigue, depression and sleep disturbance [1] which can contribute to substantial distress [2]. Previous research has revealed that people with cancer generally experience multiple symptoms concurrently, with patients reporting an average of eight [3-5]. These cancer-related symptoms can adversely impact functional status and quality of life [6,7], and can result in treatment delays and stoppages [8], making symptom management a top priority. Since symptom experiences are complex and multidimensional, addressing spirituality may be one route to support symptom management [9]. 
Interest in examining spirituality's effects on physical and mental health is expanding, with growing evidence that higher self-reported spirituality is associated with positive physical and psychological outcomes [10]. Spirituality is defined as a dynamic process whereby humans experience connection with self, others, nature and/or higher power and a sense of meaning [11-13]. Spirituality is often operationalized as spiritual well-being, including dimensions of peace, faith and meaning [14]. Spirituality and religion are separate and distinct concepts, yet they can have overlap for some patients. Religion is generally practiced within an organized structure and is focused on prayers, rituals and communal services, where spirituality involves recognizing sacredness of every human activity [15]. Spirituality can be meaningful at any stage of life, but often becomes especially important when faced with a lifethreatening illness such as cancer [15]. Prior research suggests that connection to spirituality offers a route to supportive thoughts and emotions, such as a sense of safety and comfort, when facing difficult circumstances [16], and that spirituality can serve as a positive coping resource to support adjustment to cancer and cancer-related symptoms $[9,17]$. Spirituality may also be associated with greater uptake of self-management strategies among people with cancer [18]. Based on this premise, supporting spirituality could be especially helpful when facing a range of cancer-related symptoms.

Prior research on spirituality and cancer-related symptoms has primarily focused on single-symptom outcomes such as pain [19] and depression [20], and findings have been mixed [21, 22]. Yet recent work examining coordinated symptom management across multiple cancer-related symptoms has highlighted the value of assessing and addressing co-occurring or clustered symptoms concurrently [23]. Cancerrelated symptoms, such as the pain, fatigue, and sleep disturbance cluster, have complex biopsychosocial underpinnings [4, 24]. Supporting spirituality is an under-explored area which could yield future advancements in the simultaneous management of co-occurring symptoms.

Conceptually, this work is grounded in the Dynamic Symptoms Model $[25,26]$. This theoretical foundation illustrates the complex nature of symptoms, and symptom trajectories. The Dynamic Symptoms Model describes how various antecedents give rise to multidimensional symptom experiences, and how symptom experiences have consequences across different areas of patients' lives. For the current research, our application of the model focuses on the role of spirituality as an antecedent to the experience of symptom severity, distress, and interference across four common cancer-related symptoms, pain, fatigue, depression, and sleep disturbance. Based on prior literature and on the Dynamic Symptoms Model, the current study explores the potential for spirituality to play a role in the way adults with cancer experience symptoms.

\section{Purpose}

The purpose of this research is to explore how spirituality relates to common cancer-related symptoms (pain, fatigue, depression, sleep disturbance) among a sample of adults with cancer. Aims include examining...

1) The relationship between spirituality and symptom severity (for pain, fatigue, depression, sleep disturbance). 
2) The relationship between spirituality and symptom-related distress (for pain, fatigue, depression, sleep disturbance).

3) The relationship between spirituality and overall symptom interference with daily life.

Is it hypothesized that higher levels of spirituality will be related to lower symptom severity, lower symptom-related distress and lower levels of overall symptom interference among this sample of people with cancer.

\section{Methods}

\section{Design and Sample}

The current research is a secondary analysis of data from a set of 200 solid tumor cancer patients, collected as part of a larger study which explored symptom clusters in people with solid tumor cancers [27]. All study procedures were approved by the Institutional Review Board (IRB) before beginning the research. Participants were recruited based on the following inclusion criteria: 1 ) adults ( $\geq 18$ years of age), 2) able to read and write in English, 3) diagnosis of breast, prostate, lung, melanoma, renal, or bladder cancer, and 4) receiving Day 1 of at least the third cycle of chemotherapy given in three-week intervals. Potential participations were excluded if they had 1) recent radiotherapy or surgery ( $<3$ months) or 2) cognitive impairment that would impede ability to complete study procedures.

\section{Data Collection Procedures}

Data were collected from eligible participants who were receiving chemotherapy treatment at a single clinic. Participants were enrolled on the first day (Day 1) of a new chemotherapy cycle and each received chemotherapy on a three-week cycle. Participants were provided survey packets to be completed at weekly intervals over three-weeks of ongoing cancer treatment (baseline and on days 7, 14, and 21). Although the parent study collected additional data, only relevant variables for this secondary analysis are included in this report. Demographic information was collected at baseline using a standardized selfreport questionnaire which elicited information on age, gender, partner status, race, ethnicity, education, and income. Details about cancer diagnosis and stage (I-IV), chemotherapy, and documented comorbid chronic conditions were obtained through a medical record review. To assess chronic conditions, a modified version of the Charlson Co-morbidity Index (CCI) [28] was used. In the parent study, modifications were made to include obesity $(\mathrm{BMI} \geq 30)$, hypertension, hyperlipidemia and age $>65$ [27]. Points were assigned for each chronic condition, with weighted points for conditions with especially strong associations with poor health. For the current analysis, total score on the modified CCI was used as a comorbidity score with higher scores indicating more comorbidity.

Symptoms were assessed using a modified version of the Memorial Symptom Assessment Scale (MSAS) $[29,30]$. Participants were provided a list of 41 symptoms and were asked to indicate whether any of the symptoms were present in the past week. For each symptom present, severity was rated on a Likert-type 
scale, from 1 - "slight" to 4 - "very severe". For each symptom present, participants rated how much the symptom distressed or bothered them from 0 - "not at all" to 4 - "very much". The MSAS has strong reliability ( $a=0.83-0.88)$ and evidence of validity among samples of people with cancer [29]. In the current analyses, we used ratings of four symptoms of interest - pain, difficulty sleeping, lack of energy (fatigue), and feeling sad (depression), consistent with descriptions in previous research [31].

Symptom interference with daily life was assessed with the M. D. Anderson Symptom Inventory (MDASI) Symptom Interference Subscale [32]. Participants were asked to rate how much their symptoms interfered with various aspects of their life in the past week (general activity, mood, work, relations with other people, walking, and enjoyment of life). These six items were rated from 0 - "did not interfere" to 10 - "interfered completely". The Symptom Interference subscale has been shown to have strong reliability among cancer patients $(a=0.91)$ and has evidence of content and construct validity [32].

In this secondary analysis, spirituality was assessed using a subset of items from the Fox Simple Quality of Life Scale (FSQoLS) [33]. The FSQoLS asks participants rate their level of agreement (1 - "strongly disagree" to 5 - "strongly agree") with 25 statements focused on various dimensions of quality of life. Items encompass perceptions of health, enjoyment of life, feelings of well-being, and life satisfaction over the past week. The FSQoLS has demonstrated high reliability $(a=0.93)$ and convergent validity with other QoL assessments ( $r=0.80-0.91)$ across cancer patients [33]. The FSQoLS has evidence of a twofactor structure including: 1) Quality of life factor, encompassing cognitive and affective items related to health, well-being, functioning and life satisfaction; and 2) Spirituality-based factor, including faith, life meaning, connection to family and friends [33]. For this analysis, spirituality was assessed using an aggregate mean score of four items from the spirituality-based factor. The included items encompassed areas of peace, faith, meaning and a general item, "I am spiritual."

\section{Analyses}

Data analysis was conducted in SPSS version 27. Available case analysis was employed; for each analysis, cases were included which had each of the required variables present. Only data from day 7 was included in this analysis since this is when participants demonstrated the highest symptom severity, and thus, were in need of symptom management support [27]. Symptom rating distributions were right skewed, with the majority of participants reporting low levels of severity; therefore, data for were categorized into "no severity" (score of 0 , not present), "mild severity" (score of 1 ) and "greater than mild severity" (scores $>1$ ) [27]. The same categorizing process was performed for symptom-related distress ratings. For participants who indicated that a particular symptom was not present, distress data was not applicable for that symptom. Descriptive statistics (means, standard deviations and frequencies) were used to describe the demographics of the sample. Means and standard deviations for key variables were also calculated.

To examine each of the aims, we ran a series of regressions. For Aim 1, we explored the relationship between spirituality and symptom severity with a series of four ordinal regressions, one for each symptom. An aggregate score for spirituality served as the independent variable in each model, and 
symptom severity (pain, fatigue, depression, sleep disturbance) served as dependent variables. To address Aim 2, we examined the relationship between spirituality and symptom-related distress using a similar series of four ordinal regressions. Spirituality (aggregate score) served as the independent variable and symptom-related distress (for pain, fatigue, depression, sleep disturbance) served as dependent variables. Finally, for Aim 3, we employed a linear regression to investigate the relationship between spirituality and overall symptom interference with daily life. For this analysis, spirituality (aggregate score) served as the independent variable and overall symptom interference as the dependent variable. In each regression, demographic and disease-related factors known to influence symptom experiences were included as covariates (age, sex, stage of cancer, comorbidities).

\section{Results}

The parent study screened a total of 569 patients, with 232 found to be eligible. Of these patients, 200 (86\%) enrolled in the study. Participants were predominantly female $(57.5 \%)$, white (97.3\%), and partnered $(69.6 \%)$. The mean age was $60.2(S D=12.2)$, ranging from 24 to 89 . Stage IV cancer was most common (47.8\%), and melanoma was the most frequently reported type of cancer (36.8\%). Additional participant characteristics are reported in Table 1. Severity of symptoms reported as "not present" was assumed to be " 0 ". On average, symptom severity ratings were low $(0.28-1.53)$, and symptoms were somewhat distressing (1.85-2.21) (Table 2). Symptoms created mild interference with daily life $(M=3.32, S D=2.40)$ and patients reported relatively high levels of spirituality $(M=4.13, S D=0.71)$. When categorizing symptom ratings, symptom severity was most commonly reported as "none" or "more than mild", and symptom distress was most frequently "more than mild" (Table 3). 
Table 1

Participant characteristics

\begin{tabular}{|lll|}
\hline Variable & $\mathbf{n}$ & Mean, S.D., (Range) \\
\hline Age (years) & 181 & $60.2,12.2,(24-89)$ \\
\hline Variable & $\mathrm{n}$ & $\%$ \\
\hline Gender & 104 & 57.5 \\
Female & & \\
\hline Marital status & 126 & 69.6 \\
Married/partnered & & \\
\hline Race & 177 & 97.3 \\
White & 2 & 1.1 \\
American Indian or Alaskan Native & 1 & 0.6 \\
Native Hawaiian or Pacific Islander & 1 & 0.6 \\
Other & 1 & 0.6 \\
Unknown & & \\
\hline Ethnicity Latino/a & 175 & 97.8 \\
No & & \\
\hline Education & 86 & 47.5 \\
High school/GED/Some college & 59 & 32.6 \\
Associate/Bachelor & 36 & 19.9 \\
Some graduate/master/doctoral & & \\
\hline Income & 44 & 28.9 \\
< \$40,000/year & 58 & 38.2 \\
\$40,000-\$90,000/year & 52.9 \\
$\geq 90,000 /$ year & & \\
\hline & & \\
\hline
\end{tabular}

$\%$ may not $=100 \%$ due to rounding 


\begin{tabular}{|lll|}
\hline Variable & $\mathbf{n}$ & Mean, S.D., (Range) \\
\hline Cancer Stage & 16 & 8.9 \\
II III & 30 & 16.7 \\
IV & 48 & 26.7 \\
Cancer diagnosis & 86 & 47.8 \\
Melanoma & & \\
Lung & 67 & 36.8 \\
Breast & 49 & 26.9 \\
Bladder & 46 & 25.3 \\
Prostate & 10 & 5.5 \\
Kidney & 7 & 3.8 \\
\hline \% may not = 100\% due to rounding & & \\
\hline
\end{tabular}

Table 2

Means, standard deviations, and observed ranges of key variables

\begin{tabular}{|llll|}
\hline Variable & Mean & S.D. & Observed Range \\
\hline Pain - severity $(0-4)$ & .81 & 1.11 & $0-4$ \\
\hline Fatigue - severity (0-4) & 1.53 & 1.27 & $0-4$ \\
\hline Depression - severity (0-4) & .28 & .74 & $0-4$ \\
\hline Sleep disturbance - severity (0-4) & .85 & 1.14 & $0-4$ \\
\hline Pain - distress (0-4) & 1.96 & 1.08 & $0-4$ \\
\hline Fatigue - distress (0-4) & 2.21 & .96 & $0-4$ \\
\hline Depression - distress (0-4) & 1.85 & 1.05 & $0-4$ \\
\hline Sleep disturbance - distress $(0-4)$ & 2.14 & .93 & $1-4$ \\
\hline Overall symptom interference $(0-10)$ & 3.32 & 2.40 & $.2-9.7$ \\
\hline Spirituality $(1-5)$ & 4.13 & .71 & $1.75-5$ \\
\hline
\end{tabular}


Table 3

Frequency (\%) of symptom severity and distress response categories

\begin{tabular}{|llll|}
\hline Variable & None & Mild & >Mild \\
& $\mathbf{n}(\%)$ & $\mathbf{n}(\%)$ & $\mathbf{n}(\%)$ \\
\hline Pain - severity & $105(60.0 \%)$ & $18(10.2 \%)$ & $52(29.7 \%)$ \\
\hline Fatigue - severity & $60(34.9 \%)$ & $8(4.7 \%)$ & $104(60.5 \%)$ \\
\hline Depression - severity & $154(85.6 \%)$ & $8(4.4 \%)$ & $18(10.0 \%)$ \\
\hline Sleep disturbance - severity & $105(59.6 \%)$ & $15(8.5 \%)$ & $56(31.8 \%)$ \\
\hline Pain - distress & $4(5.6 \%)$ & $25(34.7 \%)$ & $43(59.7 \%)$ \\
\hline Fatigue - distress & $2(1.8 \%)$ & $24(21.2 \%)$ & $87(77.0 \%)$ \\
\hline Depression - distress & $1(3.8 \%)$ & $10(38.5 \%)$ & $15(57.7 \%)$ \\
\hline Sleep disturbance - distress & $0(0.0 \%)$ & $20(28.1 \%)$ & $51(71.8 \%)$ \\
\hline
\end{tabular}

After controlling for covariates, higher spirituality was significantly associated with lower mean severity ratings for 3 of the 4 symptoms. Higher spirituality was significantly associated with lower severity of fatigue $(p<.003)$, depression $(p<.006)$ and sleep disturbance $(p<.004)$. Higher spirituality trended toward association with lower pain severity, although results were not significant $(p<.058)$ (Table 4). Controlling for covariates, higher spirituality was not significantly associated with lower mean distress ratings for any of the four symptoms (Table 5). Finally, after controlling for covariates, results revealed that higher spirituality was significantly associated with lower overall symptom interference $(p<.004)($ Table 6$)$. 
Table 4

Results of regression analyses exploring relationships between spirituality and symptom severity

\section{Pain - Severity}

\begin{tabular}{|c|c|c|c|c|c|c|c|}
\hline & \multirow[t]{2}{*}{ Estimate } & \multirow[t]{2}{*}{ Std. Error } & \multirow[t]{2}{*}{ Wald } & \multirow[t]{2}{*}{ df } & \multirow[t]{2}{*}{ Sig. } & \multicolumn{2}{|c|}{ 95\% Confidence Interval } \\
\hline & & & & & & Lower Bound & Upper Bound \\
\hline Spirituality & -.425 & .224 & 3.605 & 1 & .058 & -.863 & .014 \\
\hline Age & -.018 & .020 & .812 & 1 & .367 & -.057 & .021 \\
\hline Stage & -.237 & .212 & 1.247 & 1 & .264 & -.653 & .179 \\
\hline Comorbidity & .114 & .122 & .883 & 1 & .347 & -.124 & .353 \\
\hline Gender & -.271 & .339 & .639 & 1 & .424 & -.935 & .393 \\
\hline
\end{tabular}

Fatigue - Severity

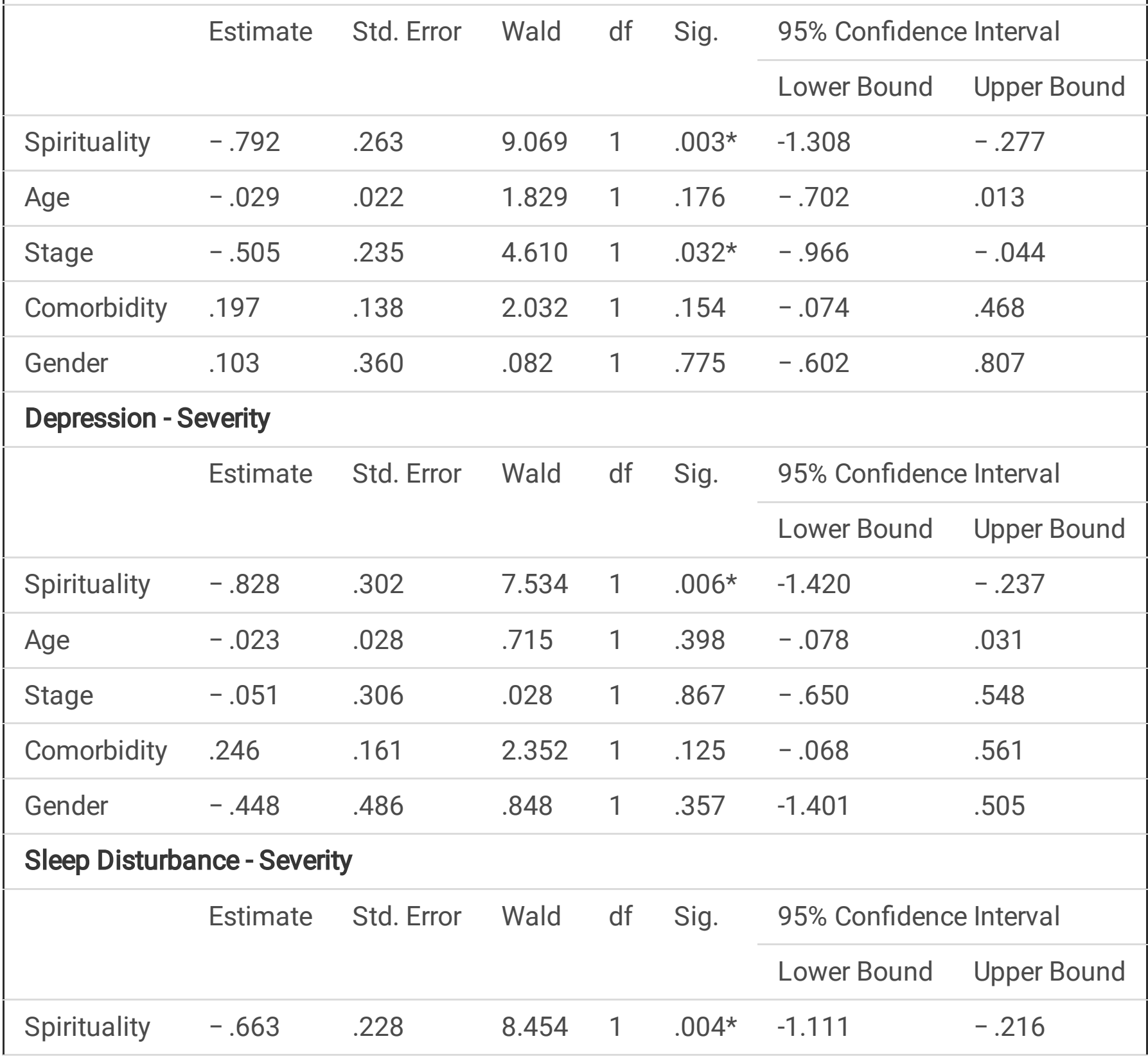




\begin{tabular}{|llllllll|}
\hline Pain - Severity & \multicolumn{7}{l|}{. } \\
\hline Age & -.011 & .020 & .291 & 1 & .589 & -.050 & .029 \\
\hline Stage & -.175 & .215 & .662 & 1 & .416 & -.596 & .246 \\
\hline Comorbidity & -.206 & .124 & .044 & 1 & .834 & -.270 & .218 \\
\hline Gender & 0.39 & .343 & .013 & 1 & .910 & -.633 & .710 \\
\hline
\end{tabular}


Table 5

Results of regression analyses exploring relationships between spirituality and symptom distress

\begin{tabular}{|c|c|c|c|c|c|c|c|}
\hline \multicolumn{8}{|c|}{ Pain - Distress } \\
\hline & \multirow[t]{2}{*}{ Estimate } & \multirow[t]{2}{*}{ Std. Error } & \multirow[t]{2}{*}{ Wald } & \multirow[t]{2}{*}{ df } & \multirow[t]{2}{*}{ Sig. } & \multicolumn{2}{|c|}{$95 \%$ Confidence Interval } \\
\hline & & & & & & Lower Bound & Upper Bound \\
\hline Spirituality & -.260 & .358 & .528 & 1 & .468 & -.916 & .441 \\
\hline Age & -.016 & .034 & .229 & 1 & .632 & -.084 & .051 \\
\hline Stage & -.343 & .310 & 1.225 & 1 & .268 & -.951 & .265 \\
\hline Comorbidity & .074 & .184 & .162 & 1 & .687 & -.287 & .436 \\
\hline Gender & -.178 & .547 & .106 & 1 & .745 & -1.249 & .894 \\
\hline \multicolumn{8}{|c|}{ Fatigue - Distress } \\
\hline & \multirow[t]{2}{*}{ Estimate } & \multirow[t]{2}{*}{ Std. Error } & \multirow[t]{2}{*}{ Wald } & \multirow[t]{2}{*}{ df } & \multirow[t]{2}{*}{ Sig. } & \multicolumn{2}{|c|}{$95 \%$ Confidence Interval } \\
\hline & & & & & & Lower Bound & Upper Bound \\
\hline Spirituality & -.274 & .346 & .628 & 1 & .428 & -.952 & .404 \\
\hline Age & .002 & .030 & .006 & 1 & .938 & -.056 & .060 \\
\hline Stage & -.178 & .298 & .355 & 1 & .551 & -.763 & .407 \\
\hline Comorbidity & -.111 & .169 & .426 & 1 & .514 & -.442 & .221 \\
\hline Gender & .257 & .482 & .284 & 1 & .594 & -.688 & 1.202 \\
\hline \multicolumn{8}{|c|}{ Depression - Distress } \\
\hline & \multirow[t]{2}{*}{ Estimate } & \multirow[t]{2}{*}{ Std. Error } & \multirow[t]{2}{*}{ Wald } & \multirow[t]{2}{*}{$\mathrm{df}$} & \multirow[t]{2}{*}{ Sig. } & \multicolumn{2}{|c|}{ 95\% Confidence Interval } \\
\hline & & & & & & Lower Bound & Upper Bound \\
\hline Spirituality & -.220 & .663 & .110 & 1 & .741 & -1.520 & 1.080 \\
\hline Age & -.033 & .086 & .147 & 1 & .702 & -.202 & .136 \\
\hline Stage & -.793 & .991 & .641 & 1 & .423 & -2.736 & 1.149 \\
\hline Comorbidity & -.488 & .469 & 1.079 & 1 & .299 & -1.407 & .432 \\
\hline Gender & -.676 & 1.096 & .381 & 1 & .537 & -2.824 & 1.472 \\
\hline \multicolumn{8}{|c|}{ Sleep Disturbance - Distress } \\
\hline & \multirow[t]{2}{*}{ Estimate } & \multirow[t]{2}{*}{ Std. Error } & \multirow[t]{2}{*}{ Wald } & \multirow[t]{2}{*}{ df } & \multirow[t]{2}{*}{ Sig. } & \multicolumn{2}{|c|}{ 95\% Confidence Interval } \\
\hline & & & & & & Lower Bound & Upper Bound \\
\hline
\end{tabular}




\begin{tabular}{|llllllll|}
\hline \multicolumn{7}{|l|}{ Pain - Distress } \\
\hline Spirituality & -.024 & .406 & .003 & 1 & .954 & -.819 & .722 \\
Age & .017 & .034 & .252 & 1 & .616 & -.050 & .084 \\
Stage & -.266 & .355 & .562 & 1 & .453 & -.962 & .430 \\
Comorbidity & .117 & .228 & .264 & 1 & .607 & -.330 & .565 \\
Gender & .173 & .602 & .082 & 1 & .744 & -1.008 & 1.353 \\
\hline
\end{tabular}

Table 6

Results of regression analyses exploring the relationship between spirituality and symptom interference with daily life

\begin{tabular}{|llllll|}
\hline & Unstandardized $\beta$ & $\begin{array}{l}\text { Coefficients } \\
\text { Std. Error }\end{array}$ & Standardized Coefficients $\beta$ & $\mathbf{t}$ & Sig. \\
\hline Spirituality & -1.116 & .383 & -.277 & -2.918 & $.004^{\star}$ \\
\hline Age & .000 & .028 & -.001 & -.010 & .992 \\
\hline Stage & -.029 & .471 & -.006 & -.062 & .951 \\
\hline Comorbidity & -.305 & .298 & -.132 & -1.026 & .307 \\
\hline Gender & -.080 & .186 & -.075 & -.430 & .668 \\
\hline
\end{tabular}

\section{Discussion}

With the growing interest in spiritual aspects of cancer care, attention to the role of spirituality in cancerrelated symptoms is becoming increasingly important. Spirituality often becomes especially salient when one is faced with a serious illness such as cancer, and satisfaction with one's sense of spirituality can support psychological adjustment to cancer [11,34]. Although prior studies indicate the value of spirituality among people with cancer, the current study provides novel insight into the relationships between spirituality and severity, distress and interference associated with multiple common cancerrelated symptoms.

Results revealed that spirituality was not significantly associated with pain severity, although results trended towards significance in the expected direction. Prior studies have reported mixed results when evaluating spirituality's role in experiences of pain [19,35-37], indicating a need for further research in this area, especially considering which types of pain (i.e., visceral, neuropathic, central sensitization, etc.) may be most closely related to spirituality. Furthermore, higher spirituality was significantly associated with lower severity of fatigue, depression and sleep disturbance. Prior literature on spirituality and fatigue is sparse, although one preliminary study found a significant inverse relationship between fatigue and spiritual well-being among people with cancer [38]. The finding that higher spirituality is associated with 
lower depression aligns with prior findings from and Nelson et al. Nelson, Rosenfeld, Breitbart and Galietta [39] and Gonzalez et al. [20], where depression was significantly associated with spirituality when examining aspects of peace, faith and meaning. Although prior qualitative work suggests the value of spirituality to support sleep among a sample of women with advanced breast cancer [9], little research has been done to assess the relationship between spirituality and sleep disturbance among cancer patients. One prior study examined spirituality and sleep quality among Muslim women with breast cancer and found that some aspects of spirituality may predict better sleep quality, although the overall correlation between spiritual well-being and quality of sleep was non-significant [40]. These findings underscore the potential importance of addressing spirituality as part of holistic symptom management, yet additional research is needed to examine the role of spirituality (and its sub-components) in the experience of cancer-related symptoms among larger and more diverse samples.

This secondary analysis revealed that spirituality was not significantly associated with symptom-related distress across any of the four symptoms. These findings contrast prior work suggesting that aspects of spirituality, such as a sense of meaning or purpose in life; belief in a higher power; and a sense of connectedness with self, others, nature, and a higher being can be psychologically supportive when facing cancer-related symptoms [34]. One potential reason for the null finding in the current study could be the decreased sample size across the analyses. If participants indicated that a symptom was not present (severity $=0$ ), then a distress rating was not applicable, resulting in varying sample sizes across the analyses ( $N=72$ for pain; $N=113$ for fatigue; $N=26$ for depression; $N=71$ for sleep disturbance). This approach resulted in smaller sample sizes for some of the analyses and restricted range, with very few participants in the "no distress" category across the four symptoms (5.5\% reported "no distress" for pain, $1.8 \%$ for fatigue, $3.8 \%$ for depression and $0 \%$ for sleep disturbance). It is also possible that spirituality is truly unrelated to distress associated with cancer symptoms, calling for further examination. Future research is needed which can examine the role of spirituality in symptom-related distress among a larger sample of people with cancer and a broader range of distress experiences.

Our results revealed that higher spirituality was significantly associated with lower symptom-related interference. This finding aligns with the idea that spirituality can serve as a psychological support when facing cancer-related symptoms, and that spirituality may contribute to adjustment to cancer and cancerrelated symptoms by providing a constructive cognitive frame on one's situation, serving as an emotional regulation strategy, or even by inspiring one to reach out for social support $[9,34]$. Findings of the current study add to the literature supporting the value of spirituality when facing cancer. Additional research is needed to determine which aspects of spirituality and which aspects of religion may be contribute to holistic management of symptoms, overall distress, and existential concerns associated with cancer. Further research exploring the distinction between spirituality and religion is also needed, while considering that involvement with religion can strengthen aspects of spirituality such as connection to others and connection with a higher power $[15,41]$.

Potential mechanisms underlying spirituality's correlation with symptom severity and interference are not yet known, calling for continued examination of these phenomena. One potential explanation is that a 
sense of connection to a higher power supports emotional regulation and greater resilience in the face of adverse experiences $[9,42]$, making symptoms more tolerable. It is also possible that people who reported high spirituality in this sample had strong connections through church or other spiritually oriented communities [42]. Social support available among spiritual community members could influence the experience of cancer-related symptom severity and distress [43]. Additionally, it must be acknowledged that although this study identified significant correlations between spirituality and symptom intensity as well as spirituality and symptom-related interference, it is not known whether spirituality influenced symptom experiences, or whether symptom experiences may influence experiences of meaning, peace, faith or overall sense of spirituality. It is also possible that these phenomena may exist in reciprocal relationship with one another. Further research is needed to offer more insight into the nature of these relationships.

Considering prior research which indicates that cancer patients and their lay caregivers perceive oncology providers as in a role to support spirituality [44], clinicians are encouraged to address spirituality as part of comprehensive care for people with cancer. Clinicians can explore spirituality with their patients through inclusive spirituality assessments, using an existential approach which could apply to patients regardless of religiosity. Interventions such as mindfulness meditation, prayer and visualization can have spiritual underpinnings and may also have the capacity to alter the experience of cancer-related symptoms $[9,45]$. These interventions can be simple to learn and easily employed across clinical settings. Overall, continued exploration of cognitive and emotional influences on cancer-related symptoms, including aspects of spirituality, could yield significant advancements in the area of symptom management for patients with advanced cancer.

\section{Limitations}

This study has several limitations which must be noted. First, this sample had a lack of diversity and is not representative of the racial and ethnic diversity among all cancer patients in the United States. The homogeneity of the sample limited us from including race or ethnicity as covariates, which should be examined in future studies. Next, this sample of cancer patients has relatively low symptom severity and distress, and relatively high spirituality. This resulted in low variability across some of the variables and restricting range which likely influenced findings. Additionally, although spirituality was measured using four items across relevant areas of the Fox Quality of Life scale, a validated assessment tool for spirituality was not employed in this study. The four items that were included in this study reflect aspects of spirituality measured in other psychometrically-sound assessment tools such as the Functional Assessment of Chronic Illness Therapy - Spiritual Well-Being scale [14], yet despite this close alignment, additional research into spirituality and cancer-related symptoms with more robust assessments of spirituality is needed. And finally, potential confounding between aspects of spirituality and cancerrelated symptoms (especially anxiety and depression) must be considered and controlled in future studies. 


\section{Conclusions}

This study highlights the significant role that spirituality can play in the experience of cancer-related symptoms. This secondary analysis revealed that higher spirituality is a predictor of lower symptom severity and symptom-related interference. Additional research is needed to examine these constructs among more diverse samples of cancer patients and to uncover the mechanisms underlying spirituality's supportive effects. Further understanding of spirituality's role in the experience of cancer-related symptoms may open avenues to innovative interventions that incorporate aspects of spirituality. Clinicians are urged to consider spiritual aspects of care such as peace, faith and meaning, as integral to holistic cancer care.

\section{Declarations}

Funding: Partial financial support was received from NINR 1P20NR018081-01 grant, Midwest Nursing Research Society (MNRS) New Investigator grant and Holden Comprehensive Cancer Center (HCCC) Diana Benz Seed grant.

Ethics approval: All study procedures were approved by the Institutional Review Board (IRB) before beginning the research.

Consent to participate: Informed consent was obtained from all individual participants included in the study.

Consent to publish: The authors affirm that human research participants provided informed consent for deidentified publication of data.

Conflicts of interest: None to disclose.

Material and/or Code availability: N/A

Authors Contributions: All authors contributed to the study conception and design. Material preparation and data collection in the parent study were performed by Dr. Catherine Cherwin. Data analyses in this secondary analysis study were performed by Dr. Megan Miller, in consultation with Dr. Kristine Kwekkeboom and Dr. Catherine Cherwin. The first draft of the manuscript was written by Dr. Megan Miller and all authors commented on previous versions of the manuscript. All authors read and approved the final manuscript.

\section{Declarations}

Partial financial support was received from NINR 1P20NR018081-01 grant, Midwest Nursing Research Society (MNRS) New Investigator grant and Holden Comprehensive Cancer Center (HCCC) Diana Benz Seed grant. All study procedures were approved by the Institutional Review Board (IRB) before beginning the research. Informed consent was obtained from all individual participants included in the study. The 
authors affirm that human research participants provided informed consent for deidentified publication of data. Authors have no Conflicts of Interest to disclose. All authors contributed to the study conception and design. Material preparation and data collection in the parent study were performed by Dr. Catherine Cherwin. Data analyses in this secondary analysis study were performed by Dr. Megan Miller, in consultation with Dr. Kristine Kwekkeboom and Dr. Catherine Cherwin. The first draft of the manuscript was written by Dr. Megan Miller and all authors commented on previous versions of the manuscript. All authors read and approved the final manuscript.

\section{References}

1. Kwekkeboom K (2016) Cancer symptom cluster management. Semin Oncol Nurs 32(4):373-382. https://doi.org/10.1016/j.soncn.2016.08.004

2. Al-Shahri MZ, Eldali AM, Al-Zahrani O (2012) Prevalence and severity of suffering among patients with advanced cancer. Support Care Cancer 20:3137-3140. https://doi.org/10.1007/s00520-012$1443-6$

3. Chang VT, Hwang SS, Feuerman M, Kasimis BS (2000) Symptom and quality of life survey of medical oncology patients at a Veterans Affairs medical center. Cancer 88(5): 1175-1183. https://doi.org/10.1002/(SICI)1097-0142(20000301)88:5<1175::AID-CNCR30>3.0.C0;2-N

4. Miaskowski C, Barsevick A, Berger A, Casagrande R, Grady P et al (2017) Advancing symptom science through symptom cluster research: Expert panel proceedings and recommendations. J Natl Cancer Inst 109(4): djw253. https://doi.org/10.1093/jnci/djw253

5. Reilly CM, Bruner DW, Mitchell SA, Minasian LM, Basch E et al (2013) A literature synthesis of symptom prevalence and severity in persons receiving active cancer treatment. Support Care Cancer 21(6):1525-1550. https://doi.org/10.1007/s00520-012-1688-0

6. Dodd M, Cho MH, Cooper BA, Miaskowski C (2019) The effect of symptom clusters on functional status and quality of life in women with breast cancer. Eur $J$ Oncol Nurs 14(2):101-110. https://doi.org/10.1016/j.ejon.2009.09.005

7. Rha S, Lee J (2017) Symptom clusters during palliative chemotherapy and their influence on functioning and quality of life. Support Care Cancer 25(5):1519-1527. https://doi.org/10.1007/s00520-016-3545-z

8. Wyatt G, Sikorskii A, Tesnjak I, Victorson I, Srkalovic G (2015) Chemotherapy interruptions in relation to symptom severity in advanced breast cancer. Support Care Cancer 23(11):3183-3191. https://doi.org/10.1007/s00520-015-2698-5

9. Miller M, Greenwalt K, Lehto R, Wu H-S, Moser J et al (2021) Pain and spirituality among women with advanced breast cancer: Insights from a phenomenological study. Cancer Care Research Online 1(1):1-7. https://doi.org/10.1097/CR9.0000000000000001

10. Jim H, Pustejovsky J, Park C, Danhauer S, Sherman A et al (2015) Religion, spirituality, and physical health in cancer patients: A meta-analysis. Cancer 121(21):3760-3768.

https://doi.org/10.1002/cncr.29353

Page 17/20 
11. Steinhauser K, Fitchett G, Handzo G, Johnson K, Koenig H et al (2017) State of the science of spirituality and palliative care research part I: Definitions, measurement, and outcomes. J Pain Symptom Manage 54(3):428-440. https://doi.org/10.1016/j.jpainsymman.2017.07.028

12. Sun K, So Young C, Jin Sook K (2017) Evolutionary concept analysis of spirituality. J Korean Acad Nurs 47(2):242-256. https://doi.org/10.4040/jkan.2017.47.2.242

13. Weathers E, McCarthy G, Coffey A (2016) Concept analysis of spirituality: An evolutionary approach. Nurs Forum 51(2):79-96. https://doi.org/10.1111/nuf.12128

14. Peterman A, Fitchett G, Brady M, Hernandez L, Cella D (2002) Measuring spiritual well-being in people with cancer: The Functional Assessment of Chronic Illness Therapy-Spiritual Well-Being Scale (FACIT-Sp). Ann Behav Med 24(1):49-58. https://doi.org/10.1207/S15324796ABM2401_06

15. Balducci L (2019) Geriatric oncology, spirituality, and palliative care. J Pain Symptom Manage 57(1):171-175. https://doi.org/10.1016/j.jpainsymman.2018.05.009

16. Renz M, Reichmuth O, Bueche D, Traichel B, Schuett Mao M et al (2018) Fear, pain, denial, and spiritual experiences in dying processes. Am J Hosp Palliat Med 35(3):478-449. https://doi.org/10.1177/1049909117725271

17. Cheng Q, Liu X, Li X, Wang Y, Mao T et al (2019) Improving spiritual well-being among cancer patients: Implications for clinical care. Support Care Cancer 27(9): 3403-3409. https://doi.org/0.1007/s00520-019-4636-4

18. Yeager K, Sterk C, Quest T, Dilorio C, Vena C et al (2016) Managing one's symptoms: A qualitative study of low-income African Americans with advanced cancer. Cancer Nurs 39(4):303-312. https://doi.org/10.1097/NCC.0000000000000284

19. Miller M, Xu D, Lehto R, Moser J, Wu H-S et al (2021) Pain and spirituality outcomes among women with advanced breast cancer participating in a randomized controlled trial of foot reflexology. Oncol Nurs Forum 48(1):31-43. https://doi.org/10.1188/21.0NF.31-43

20. Gonzalez P, Castañeda SF, Dale J, Medeiros EA, Buelna C et al (2014) Spiritual well-being and depressive symptoms among cancer survivors. Support Care Cancer 22(9):2393-2400. https://doi.org/10.1007/s00520-014-2207-2

21. Chaar EA, Hallit S, Hajj A, Aaraj R, Kattan J et al (2018) Evaluating the impact of spirituality on the quality of life, anxiety, and depression among patients with cancer: An observational transversal study. Support Care Cancer 88(5):2581-2590. https://doi.org/10.1007/s00520-018-4089-1

22. Visser A, de Jager Meezenbroek E, Garssen B (2018) Does spirituality reduce the impact of somatic symptoms on distress in cancer patients? Cross-sectional and longitudinal findings. Soc Sci Med 214:57-66. https://doi.org/10.1016/j.socscimed.2018.08.012

23. Kwekkeboom K, Wieben A, Stevens J, Tostrud L, Montgomery K (2020) Guideline-recommended symptom management strategies that cross over two or more cancer symptoms. Oncol Nurs Forum 47(5):498-511. https://doi.org/10.1188/20.0NF.498-511

24. Kwekkeboom K, Tostrud L, Costanzo E, Coe C, Serlin R et al (2018) The role of inflammation in the pain, fatigue, and sleep disturbance symptom custer in advanced cancer. J Pain Symptom Manage 
55(5):1286-1295. https://doi.org/10.1016/j.jpainsymman.2018.01.008

25. Brant J, Beck S, Miaskowski C (2009) Building dynamic models and theories to advance the science of symptom management research. J Adv Nurs 66(1):228-240. https://doi.org/10.1111/j.13652648.2009.05179.x

26. Brant J, Dudley W, Beck S, Miaskowski C (2016) Evolution of the Dynamic Symptoms Model. Oncol Nurs Forum 43(5):651-654. https://doi.org/10.1188/16.ONF.651-654

27. Saeidzadeh S, Perkhounkova Y, Gilbertson-White S, Cherwin C (2021) The influence of multiple chronic conditions on symptom clusters in people with solid tumor cancers. Cancer Nurs [Online ahead of print]. https://doi.org/10.1097/NCC.0000000000000915

28. Charlson ME, Pompei P, Ales KL, MacKenzie CR (1987) A new method of classifying prognostic comorbidity in longitudinal studies: Development and validation. J Chronic Dis 40(5):373-383. https://doi.org/10.1016/0021-9681(87)90171-8

29. Portenoy RK, Thaler HT, Kornblith AB, Lepore JM, Freidlander-Klar H et al (1994) The Memorial Symptom Assessment Scale: An instrument for the evaluation of symptom prevalence, characteristics and distress. Eur J Cancer 30(9):1326-1336. https://doi.org/10.1016/09598049(94)90182-1

30. Cherwin C, Kwekkeboom K (2016) Prevalence, duration, severity, and distress of chemotherapyrelated gastrointestinal symptoms in patients with a hematologic malignancy. Oncol Nurs Forum 43(5):561-571. https://doi.org/10.1188/16.0NF.43-05AP

31. Kirkova J, Davis M, Walsh D, Tiernan E, O'Leary N et al (2006) Cancer symptom assessment instruments: A systematic review. J Clin Oncol 24(9):1459-1473. https://doi.org/10.1200/JC0.2005.02.8332

32. Cleeland CS, Mendoza TR, Wang XS, Chou X, Harle S, et al. (2000) Assessing symptom distress in cancer patients: The M.D. Anderson Symptom Inventory. Cancer 89(7): 1634-1646. https://doi.org/10.1002/1097-0142(20001001)89:7<1634::aid-cncr29>3.0.co;2-v

33. Fox S (2004) Preliminary psychometric testing of the Fox Simple Quality-of-Life Scale. J Neurosci Nurs 36(6):157-166. https://doi.org/10.1097/01376517-200406000-00007

34. Gaston-Johansson F, Haisfield-Wolfe M, Reddick B, Goldstein N, Lawal T (2013) The relationships among coping strategies, religious coping, and spirituality in African American women with breast cancer receiving chemotherapy. Oncol Nurs Forum 40(2):120-131.

https://doi.org/10.1188/13.ONF.120-131

35. Bai J, Brubaker A, Meghani S, Bruner D, Yeager K (2018) Spirituality and quality of life in black patients with cancer pain. J Pain Symptom Manage 56(3):390-398.

https://doi.org/10.1016/j.jpainsymman.2018.05.020

36. Delgado-Guay MO, Chisholm GB, Williams J, Frisbee-Hume S, Ferguson S et al (2016) Frequency, intensity, and correlates of spiritual pain in advanced cancer patients assessed in a supportive/palliative care clinic. Palliat Support Care 14(4):341-348.

https://doi.org/10.1017/S147895151500108X

Page 19/20 
37. Wang Y, Lin C (2016) Spiritual well-being may reduce the negative impacts of cancer symptoms on the quality of life and the desire for hastened death in terminally ill cancer patients. Cancer Nurs 39(4):E43-E50. https://doi.org/10.1097/NCC.0000000000000298

38. Lewis S, Salins N, Rao R, Kadam A (2014) Spiritual well-being and its influence on fatigue in patients undergoing active cancer directed treatment: A correlational study. J Cancer Res Ther 10(3):676680. https://doi.org/10.4103/0973-1482.138125

39. Nelson C, Rosenfeld B, Breitbart W, Galietta M (2002) Spirituality, religion, and depression in the terminally ill. Psychosomatics 43(3):213-220. https://doi.org/10.1176/appi.psy.43.3.213

40. Khoramirad A, Mousavi M, Dadkhahtehrani T, Pourmarzi D (2014) Relationship between sleep quality and spiritual well-being/religious activities in Muslim women with breast cancer. J Relig Health 54(6):2276-2285. https://doi.org/10.1007/s10943-014-9978-0

41. Sherman A, Merluzzi T, Pustejovsky J, Park C, George L et al (2015) A meta-analytic review of religious or spiritual livolvement and social health among cancer patients. Cancer 121(21):37793788. https://doi.org/10.1002/cncr.29352

42. Alcorn S, Balboni M, Prigerson H, Reynolds A, Phelps A et al (2010) If God wanted me yesterday, I wouldn't be here today": Religious and spiritual themes in patients' experiences of advanced cncer. Journal of Palliative Med 13(5):581-588. https://doi.org/10.1089/jpm.2009.0343

43. Galloway S, Meadors D, Boselli D, Walsh D (2019) Anxiety, depression, pain, and social support in a large representative cancer population. In American Society for Clinical Oncology 2019 Annual Meeting

44. Taylor E (2003) Nurses caring for the spirit: Patients with cancer and family caregiver expectations. Oncol Nurs Forum 30(4):585-590. https://doi.org/10.1188/03.0NF.585-590

45. Anderson J, Taylor A (2012) Use of complementary therapies for cancer symptom management: Results of the 2007 National Health Interview Survey. J Altern Complement Med 18(3):235-241. https://doi.org/10.1089/acm.2011.0022 